\title{
Pembuatan dan Karakterisasi Sifat Fisis Komposit Multilayer Serat Rami
}

\author{
Naila Hilmiyana Syifa*, Agus Yulianto, Upik Nurbaiti \\ Pendidikan Fisika, Program Pasca Sarjana, Universitas Negeri Semarang \\ *Email: nailahilmiyanasyifa@ students.unnes.ac.id
}

Received: 11 Juli 2021; $\quad$ Accepted: 25 September 2021;

Published: 23 Oktober 2021

DOI: http://dx.doi.org/10.29303/jpft.v7i2.2783

\begin{abstract}
The use of composites as an innovative new material is increasing. Composites are made from two or more materials that have different properties. This research was conducted to make multilayer composites and determine the effect of variations in the number of arrangements and the direction of the fiber angles on the physical properties of composites made from ramie fiber and epoxy. The physical properties of the composites analyzed in this study were density, porosity, water absorption, and thickness expansion. The composites in this study were made using the hand layup method with a volume fraction ratio of $30 \%$ and the ratio of epoxy and hardener was 2: 1 . Before the composite was made, ramie fibers were soaked in 5\% NaOH for 2 hours. This study succeeded in making epoxy ramie multilayer composites with variations in the number of arrangements and the direction of the fiber angles. Variations in the number of layers and the direction angle of the ramie fiber in the composite affect the density and porosity of the composite. Variations in the direction of the ramie fiber in the composite affect the water absorption of the composite. Variations in the number and direction of ramie fiber in the composite did not significantly affect the thickness of the composite.
\end{abstract}

Keywords: Multilayer Composites; Physical Properties; Ramie Fiber

PENDAHULUAN

Teknologi berkembang sangat pesat di segala bidang kehidupan manusia, termasuk bidang material. Perkembangan teknologi mendorong manusia agar mampu menemukan bahan baru yang belum terungkap maupun kombinasi dari bahan yang sudah ada, seperti komposit. Komposit merupakan material yang tersusun atas dua bahan atau lebih. Masing-masing bahan penyusun komposit memiliki sifat berbeda yang kemudian akan menjadi satu material baru dengan sifat yang berbeda pula (Silalahi et al., 2013). Sifat komposit hasil gabungan berbagai bahan ini diharapkan dapat memperbaiki kelemahan sifat-sifat penyusunnya. Beberapa kelemahan sifat bahan penyusun yang dapat diperbaiki adalah kekuatan, kekakuan, ketahanan korosi, ketahanan pemakaian, ketahanan gesek, insulasi panas, umur lelah, insulasi akustik, dan pengaruh terhadap temperatur (Wibowo \& Ningsih, 2018).
Komposit umumnya tersusun atas dua komponen, yaitu bahan penguat (reinforcement) dan bahan pengikat (matrix). Bahan penguat dapat berasal dari serat alami maupun serat sintesis. Penggunaan serat alami semakin dikembangkan dalam teknologi hijau (green technology) dalam ilmu material melalui pengembangan komposit yang diperkuat serat alami. Perkembangan produk teknik berkinerja tinggi yang terbuat dari sumber daya alam meningkat di seluruh dunia dari hari ke hari. Ada peningkatan minat pada bahan alam yang menunjukkan upaya penggunaan sumber daya terbarukan secara efisien. Alasan utama penggunaan bahan bio-komposit adalah biaya serat alami (harga serat alam lebih murah daripada serat kaca), pengurangan berat (serat alam beratnya setengah dari serat kaca), daur ulang (komposit serat alam lebih mudah untuk didaur ulang) dan keinginan untuk menggunakan produk ramah lingkungan (Faruk et al., 2014). 
Serat alami yang dapat digunakan untuk komposit antara lain serat rami, serat kulit jagung, serat batang pisang, serat daun nanas, serat sabut kelapa, dan serat ijuk. Dalam penelitian ini serat alam yang digunakan adalah serat rami. Serat rami umunya digunakan sebagai benang jahit industri, bahan pengemas, jaring ikan, dan kain penyaring. Serat rami juga dapat dibuat menjadi kain untuk perabotan rumah tangga (kain pelapis, kanvas) dan pakaian, serta pembuatan kertas (Mohammed et al., 2015). Pemilihan serat rami dalam penelitian ini didasarkan pada pertimbangan atas potensi serat rami di Indonesia yang berlimpah dan belum termanfaatkan secara baik. Penggunaan serat rami sebagai bahan penguat komposit diharapkan dapat meningkatkan nilai jualnya.

Komposit yang diperkuat serat biasanya digunakan dalam bentuk laminasi. Sebuah laminasi dibuat dengan mengikat dua atau lebih lamina bersama-sama. Lamina biasanya terbuat dari serat paralel yang diatur dalam matriks polimer pada beberapa fraksi volume konstan. Laminasi dapat dirakit dengan orientasi serat yang berbeda (Reddy \& Mandava, 2013). Gambar 1 menunjukkan lamina dengan orientasi sudut yang berbeda. Sifat fisis dan mekanik komposit dipengaruhi oleh orientasi serat dalam lamina dan urutan perakitannya dalam laminasi.

Bahan pengikat yang dapat digunakan untuk komposit ada banyak, salah satunya yaitu resin epoksi. Beberapa keunggulan resin epoksi dibandingkan dengan polimer lain adalah keaktifan permukaan tinggi, daya pembasahan baik, kekuatan kohesif tinggi, tidak mengkerut, dan sifatnya dapat diubahubah dengan memilih resin hardener yang tepat (Muslim et al., 2013).

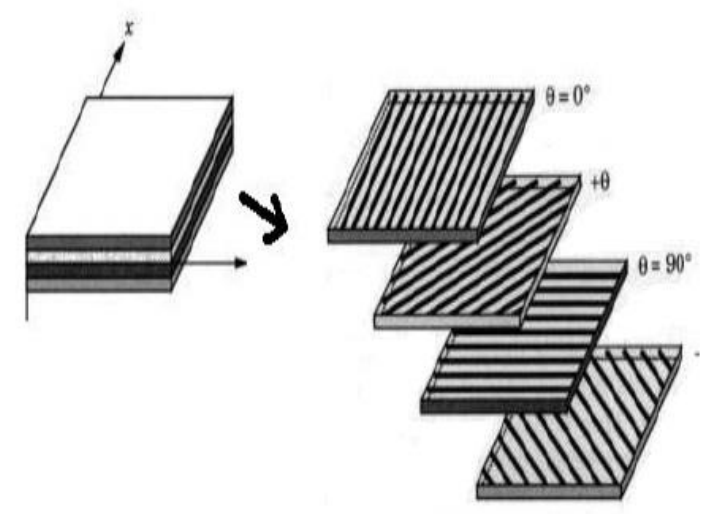

Gambar 1. Komposit yang diperkuat serat laminasi (Reddy \& Mandava, 2013)

Penelitian terkait komposit serat rami epoksi yang dilakukan oleh Soemardi et al., (2009) menyimpulkan bahwa komposit lamina serat rami epoksi berpotensi untuk dikembangkan lebih lanjut sebagai material alternatif dalam pembuatan soket prostesis atas lutut pada fraksi volume 40-50\%. Adapun penelitian Mujiono et al., (2017) berhasil mengembangkan komposit rami epoksi sebagai panel antipeluru. Hasil dari penelitian tersebut yaitu komposit rami epoksi dengan 14 susunan lamina dengan fraksi volume $60 \%$ mampu menahan penetrasi peluru pada standar level III-A NIJ.

Hasil penelitian Munasir (2011) menunjukkan kekuatan tarik terbesar terdapat pada bahan komposit dengan orientasi serat searah dibanding komposit tanpa serat (1,06:1). Dalam penelitian tersebut disarankan agar dapat dibuat bahan komposit multilayer dengan perbedaan orientasi serat pada tiap lapisnya.

Dari masalah-masalah pada penelitian diatas penulis tertarik untuk membuat penelitian terkait pengaruh variasi arah susunan lapis komposit pada komposit multilayer serat rami epoksi terhadap sifat fisis yang meliputi densitas, porositas, daya serap air, dan pengembangan tebal. Arah susunan lapis komposit yang dimaksud adalah memvariasikan susunan $0^{\circ}$ dan $90^{\circ}$. 
Tujuan dari penelitian ini adalah membuat komposit multilayer dengan variasi arah susunan lapis komposit pada komposit berbahan serat rami epoksi. Komposit multilayer dibuat untuk mengetahui pengaruh variasi arah susunan lapis komposit terhadap sifat fisis komposit yang berupa densitas, porositas, daya serap air, dan pengembangan tebal.

Penelitian ini bermanfaat untuk memberikan solusi penggunaan material komposit yang tepat guna. Selain itu penelitian ini dapat dijadikan referensi untuk penelitian selanjutnya terkait material komposit multilayer dari serat rami dengan resin epoksi.

\section{METODE PENELITIAN}

Komposit serat rami dengan matriks epoksi dibuat dengan metode hand layup. Sebelum dibuat komposit, serat rami direndam dengan $\mathrm{NaOH} 5 \%$ selama 2 jam, karena menurut Diharjo (2006) kekuatan dan regangan tarik komposit rami-polyester memiliki harga optimum untuk perlakuan perendaman serat dengan $\mathrm{NaOH}$ 5\% selama 2 jam. Dalam penelitian ini menggunakan fraksi volume serat $30 \%$ dengan pertimbangan ukuran tebal cetakan yang sangat tipis. Adapun perbandingan resin epoksi dan hardener yang digunakan adalah $2: 1$.

Langkah-langkah pembuatan komposit multilayer serat rami-epoksi, yaitu cetakan diolesi dengan wax, kemudian matriks (campuran epoksi dan hardener) dituang ke dalam cetakan dan diratakan, lalu serat rami diletakkan di atas matriks dan ditata supaya merata diseluruh permukaan cetakan, selanjutnya lapisan komposit dibuat dengan menyusun matriks-serat-matriksserat-matriks sesuai jumlah lapisan yang telah ditentukan, kemudian cetakan ditutup dengan kaca dan dijepit dengan paper clip, lalu beban diletakkan di atas cetakan untuk menambah tekanan, kemudian komposit dibiarkan selama \pm 24 jam agar kering, komposit yang telah kering diambil dengan skrap atau kape, setelah itu komposit dipotong dengan gerinda.

Pengujian sifat fisis komposit dalam penelitian ini meliputi densitas, porositas, daya serap air, dan pengembangan tebal.

\section{Densitas}

Menurut Perdana et al., (2018) densitas merupakan besaran fisis, perbandingan massa dengan volume benda. Pengukuran densitas yang berbentuk padat menggunakan metode Archimedes sebagai berikut.

$$
\rho=\frac{m_{s}}{\left(m_{b}-m_{g}\right)} \times \rho_{H_{2} O}
$$

Dengan:

$\rho \quad=$ densitas material $\left(\mathrm{gr} / \mathrm{cm}^{3}\right)$

$m_{s}=$ massa kering (gr)

$m_{g}$ = massa material digantung dalam air (gr)

$m_{b}=$ massa material setelah direndam dengan air (gr)

$\rho_{\mathrm{H}_{2} \mathrm{O}}=$ massa jenis air $\left(\mathrm{gr} / \mathrm{cm}^{3}\right)$

\section{Porositas}

Perdana et al., (2018) menyebutkan porositas dapat didefenisikan sebagai perbandingan antara jumlah volume ruang kosong atau pori-pori yang dimiliki oleh material padat terhadap jumlah dari volume material itu sendiri. Dalam Firdaus et al., (2019) porositas merupakan udara yang terperangkap dalam komposit (void). Void disebabkan tekanan yang tidak rata, resin yang menguap, udara yang terperangkap dalam resin pada saat pengadukan, atau pencampuran yang tidak homogen. Pengujian porositas dengan metode perendaman ke dalam air selama 24 jam sesuai dengan ASTM D570-98. Untuk menentukan porositas, digunakan persamaan berikut.

$$
\mathrm{P}=\frac{m_{b}-m_{s}}{\left(m_{b}-m_{g}\right)} \times 100 \%
$$


Dengan:

$P \quad=$ porositas material $(\%)$

$m_{s} \quad=$ massa kering $(\mathrm{gr})$

$m_{g}$ = massa material digantung dalam air (gr)

$m_{b}=$ massa material setelah direndam dengan air (gr)

\section{Daya Serap Air}

Daya serap air adalah salah satu sifat

fisis komposit yang menunjukkan kemampuan komposit untuk menyerap air setelah direndam di dalam air. Uji daya serap air dimaksudkan untuk mengetahui batas kemampuan komposit dalam menyerap air sampai batas maksimal (Izaak et al., 2013). Spesimen uji ditimbang massa awalnya $\left(\mathrm{m}_{1}\right)$, kemudian direndam dalam air selama 24 jam dan ditiriskan lalu ditimbang massa akhirnya $\left(\mathrm{m}_{2}\right)$. Nilai daya serap air dihitung dengan persamaan berikut.

$$
\text { DSA }=\frac{m_{2}-m_{1}}{m_{1}} \times 100 \%
$$

Dengan:

$D S A=$ daya serap air $(\%)$

$m_{1}=$ massa sebelum direndam (gr)

$m_{2}=$ massa setelah direndam selama 24 jam (gr)

\section{Pengembangan Tebal}

Pengembangan tebal merupakan bertambahnya dimensi komposit dengan bertambahnya ketebalan dari komposit tersebut. Tingginya nilai pengembangan tebal papan partikel dapat disebabkan oleh tingkat absorpsi air oleh sifat fisik bahan baku dan sifat perekat yang digunakan. Penyerapan air dan pengembangan tebal adalah sifat fisik yang terkait dengan stabilitas dimensi papan (Purwanto, 2016). Perhitungan pengembangan tebal didasarkan pada selisih tebal sebelum $\left(\mathrm{t}_{1}\right)$ dan setelah $\left(\mathrm{t}_{2}\right)$ perendaman dengan air selama 24 jam (Roihan et al., 2015). Pengujian pengembangan tebal ini dilakukan bersamaan dengan pengujian daya serap air. Nilai pengembangan tebal dihitung persamaan berikut.

$$
\mathrm{PT}=\frac{t_{2}-t_{1}}{t_{1}} \times 100 \%
$$

Dengan:

$P T=$ pengembangan tebal $(\%)$

$m_{1}=$ tebal sebelum direndam $(\mathrm{cm})$

$m_{2}=$ tebal setelah direndam selama 24 jam (cm)

\section{HASIL DAN PEMBAHASAN}

Berikut ini hasil dan pembahasan sifat fisis komposit multilayer serat rami-epoksi.

\section{Hasil \\ Densitas}

Penguiian densitas setiap variasi komposit adalah 3 spesimen, sehingga total sampel yang diuji adalah 27 spesimen, kemudian dicari rata-rata densitasnya. Pengujian densitas dilakukan dengan cara penimbangan spesimen. Spesimen ditimbang dalam keadaan kering sempurna, kemudian ditimbang dalam keadaan di dalam air, dan ditimbang dalam keadaan basah setelah direndam di dalam air (Perdana et al., 2018).

Tabel 1. Hasil densitas komposit multilayer

\begin{tabular}{llc}
\multicolumn{3}{c}{ serat rami } \\
sumlah
\end{tabular}

\section{Porositas}

Proses pengujian porositas sama halnya dengan proses uji densitas yaitu dilakukan dengan cara penimbangan. 
Tabel 2. Hasil porositas komposit multilayer

\begin{tabular}{|c|c|c|}
\hline \multicolumn{3}{|c|}{ rami } \\
\hline $\begin{array}{c}\text { Jumlah } \\
\text { susunan }\end{array}$ & $\begin{array}{c}\text { Arah } \\
\text { susunan }\end{array}$ & $\begin{array}{c}\text { Porositas } \\
(\%)\end{array}$ \\
\hline \multirow[t]{3}{*}{2} & $0^{\circ}+0^{\circ}$ & 22,01 \\
\hline & $0^{\circ}+90^{\circ}$ & 9,57 \\
\hline & $90^{\circ}+90^{\circ}$ & 20,48 \\
\hline \multirow[t]{3}{*}{3} & $0^{\circ}+0^{\circ}+0^{\circ}$ & 20,63 \\
\hline & $0^{\circ}+90^{\circ}+0^{\circ}$ & 9,04 \\
\hline & $90^{\circ}+90^{\circ}+90^{\circ}$ & 11,89 \\
\hline \multirow[t]{3}{*}{4} & $0^{\circ}+0^{\circ}+0^{\circ}+0^{\circ}$ & 22,98 \\
\hline & $0^{\circ}+90^{\circ}+0^{\circ}+90^{\circ}$ & 10,41 \\
\hline & $90^{\circ}+90^{\circ}+90^{\circ}+90^{\circ}$ & 13,87 \\
\hline
\end{tabular}

\section{Daya Serap Air}

Proses pengujian daya serap dilakukan dengan cara penimbangan spesimen setelah direndam. Untuk mendapatkan nilai optimum uji daya serap air, maka dilakukan perendaman pada spesimen pada batas waktu tertentu (Izaak et al., 2013). Pada penelitian ini spesimen direndam selama 24 jam.

Tabel 3. Hasil daya serap air komposit multilayer serat rami

\begin{tabular}{llc}
\hline $\begin{array}{c}\text { Jumlah } \\
\text { susunan }\end{array}$ & \multicolumn{1}{c}{$\begin{array}{c}\text { Arah } \\
\text { susunan }\end{array}$} & $\begin{array}{c}\text { Daya serap air } \\
(\%)\end{array}$ \\
\hline 2 & $0^{\circ}+0^{\circ}$ & 2,75 \\
& $0^{\circ}+90^{\circ}$ & 4,04 \\
& $90^{\circ}+90^{\circ}$ & 4,56 \\
3 & $0^{\circ}+0^{\circ}+0^{\circ}$ & 4,17 \\
& $0^{\circ}+90^{\circ}+0^{\circ}$ & 2,74 \\
4 & $90^{\circ}+90^{\circ}+90^{\circ}$ & 4,09 \\
& $0^{\circ}+0^{\circ}+0^{\circ}+0^{\circ}$ & 3.60 \\
& $0^{\circ}+90^{\circ}+0^{\circ}+90^{\circ}$ & 3,14 \\
& $90^{\circ}+90^{\circ}+90^{\circ}+90^{\circ}$ & 4,97 \\
\hline
\end{tabular}

\section{Pengembangan Tebal}

Proses pengujian pengembangan tebal dilakukan dengan cara pengukur tebal spesimen setelah direndam. Pengukuran pengembangan tebal dilakukan bersamaan dengan pengukuran daya serap air (Roihan et al., 2015). Pada penelitian ini spesimen direndam selama 24 jam.
Tabel 4. Hasil pengembangan tebal komposit multilayer serat rami

\begin{tabular}{llc}
\hline $\begin{array}{c}\text { Jumlah } \\
\text { susunan }\end{array}$ & \multicolumn{1}{c}{$\begin{array}{c}\text { Arah } \\
\text { susunan }\end{array}$} & $\begin{array}{c}\text { Pengembangan } \\
\text { tebal }(\%)\end{array}$ \\
\hline 2 & $0^{\circ}+0^{\circ}$ & 3,64 \\
& $0^{\circ}+90^{\circ}$ & 1,72 \\
& $90^{\circ}+90^{\circ}$ & 1,08 \\
3 & $0^{\circ}+0^{\circ}+0^{\circ}$ & 0,67 \\
& $0^{\circ}+90^{\circ}+0^{\circ}$ & 1,17 \\
4 & $90^{\circ}+90^{\circ}+90^{\circ}$ & 4,73 \\
& $0^{\circ}+0^{\circ}+0^{\circ}+0^{\circ}$ & 1,86 \\
& $0^{\circ}+90^{\circ}+0^{\circ}+90^{\circ}$ & 5,44 \\
& $90^{\circ}+90^{\circ}+90^{\circ}+90^{\circ}$ & 1,11 \\
\hline
\end{tabular}

\section{Pembahasan}

Densitas

Dari Tabel 1 di atas, arah susunan serat mempengaruhi densitas pada setiap lapisan komposit. Densitas terbesar pada setiap lapisan terdapat pada arah susunan seragam $0^{\circ}$. adapun densitas terkecil pada setiap lapisan terdapat pada arah susunan gabungan $0^{\circ}$ dan $90^{\circ}$. Densitas paling besar terdapat pada komposit empat lapis pada susunan $0^{\circ}$ $+0^{\circ}+0^{\circ}+0^{\circ}$ yaitu $8,11 \mathrm{gr} / \mathrm{cm}^{3}$. Sedangkan densitas paling kecil adalah komposit dua lapis pada susunan $0^{\circ}+90^{\circ}$ yaitu 6,08 $\mathrm{gr} / \mathrm{cm}^{3}$.

Menurut SNI 01-4449-2006 dalam Nuryati et al., (2020) bahwa komposit dapat diklasifikasikan berdasarkan kerapatannya. Papan serat kerapatan rendah (PSKR) yaitu papan serat yang memiliki kerapatan $<0,40$ $\mathrm{gr} / \mathrm{cm}^{3}$. Papan serat kerapatan sedang (PSKS) yaitu papan serat yang memiliki kerapatan 0,40-0,84 gr/ $\mathrm{cm}^{3}$. Adapun papan serat kerapatan tinggi (PSKT) yaitu papan serat yang memiliki kerapatan $>0,84 \mathrm{gr} / \mathrm{cm}^{3}$. Berdasarkan klasifikasi tersebut, maka komposit rami-epoksi pada penelitian ini merupakan jenis papan serat kerapatan tinggi.

Menurut Naidu et al., (2017) tentang tinjauan sifat kimia dan fisik dari komposit yang diperkuat serat alami, densitas komposit serat rami adalah $1,5 \mathrm{gr} / \mathrm{cm}^{3}$. Terdapat perbedaan antara hasil penelitian 
ini dikarenakan kurangnya tekanan dalam pembuatan komposit. Hal ini ditunjukkan dengan tebal cetakan komposit adalah 0,2 $\mathrm{cm}$ namun tebal komposit yang dihasilkan adalah lebih dari $0,2 \mathrm{~cm}$.

\section{Porositas}

Tabel 2 menunjukkan arah susunan serat mempengaruhi porositas pada setiap variasi lapisan komposit. Pada komposit dua lapis, porositas terbesar terdapat pada komposit dengan arah susunan $0^{\circ}$. Hal yang sama terjadi pada komposit tiga lapis dan empat lapis. Adapun porositas terkecil terdapat pada komposit dengan arah susunan gabungan $0^{\circ}$ dan $90^{\circ}$ pada komposit dua lapis, tiga lapis, dan empat lapis. Porositas adalah rongga atau celah pada komposit yang disebabkan adanya udara yang terjebak pada saat proses kompaksi, sehingga partikel serat tidak dapat dengan baik mengisi rongga atau celah pada bahan komposit tersebut. Semakin besar porositas berarti semakin banyak rongga atau celah pada bahan komposit.

Pada penelitian ini porositas terbesar terdapat pada komposit multilayer dengan arah susunan $0^{\circ}$ karena arah susunan yang seragam menyebabkan lebih banyak gas yang terjebak dalam cetakan pada saat proses pembuatan komposit. Sedangkan porositas pada komposit multilayer dengan arah susunan gabungan $0^{\circ}$ dan $90^{\circ}$ lebih kecil karena gas yang terjebak dapat diminimalisir dengan perbedaan arah susunan serat. Perbedaan arah susunan serat membuat serat saling mengisi rongga yang kosong pada cetakan.

Hubungan antara densitas dan porositas suatu benda yaitu berbanding terbalik. Artinya jika densitas besar, maka porositas kecil. Hal ini dikarenakan densitas merupakan nilai kerapatan partikel dalam suatu benda, sedangkan untuk porositas merupakan tingkat adanya rongga diantara partikel-partikel benda. Namun dalam penelitian ini, spesimen dengan densitas yang besar memiliki porositas yang juga besar. Hal ini terjadi dikarenakan ukuran spesimen hasil pemotongan yang tidak sama sehingga mempengaruhi massa spesimen yang diuji. Selain itu juga dikarenakan adanya matriks yang keluar dari cetakan saat cetakan ditekan dengan paper clip dan beban.

\section{Daya Serap Air}

Tabel 3 menunjukkan bahwa setelah perendaman selama 24 jam, daya serap air tertinggi terdapat pada komposit empat lapis dengan arah susunan $90^{\circ}+90^{\circ}+90^{\circ}+90^{\circ}$ yaitu $4,97 \%$. Sedangkan daya serap air terendah terdapat pada komposit empat lapis dengan arah susunan $0^{\circ}+90^{\circ}+0^{\circ}+90^{\circ}$ yaitu $2,14 \%$.

Berdasarkan Gambar 3.3, variasi arah susunan komposit mempengaruhi daya serap air. Pada arah susunan campuran $0^{\circ}$ dan $90^{\circ}$ cenderung menghasilkan daya serap air yang rendah. Hal ini dikarenakan pada arah susunan campuran, lebih sedikit rongga udara yang dapat diisi oleh air. Sebagaimana porositas arah susunan campuran lebih kecil dibandingkan arah susunan yang seragam. Sedangkan untuk arah susunan seragam $90^{\circ}$ menghasilkan daya serap air yang tinggi. Hal ini disebabkan oleh pada susunan $90^{\circ}$, ukuran serat rami lebih pendek, sehingga mempermudah air masuk ke dalam rongga komposit.

Perbedaan daya serap air pada setiap komposit disebabkan oleh perbedaan banyaknya air yang masuk mengisi rongga komposit selama proses perendaman. Semakin besar persentase daya serap air, maka semakin besar pula air yang masuk mengisi rongga komposit.

Penyerapan air oleh suatu komposit disebabkan karena adanya ikatan hidrogen yang terbentuk antara gugus $\mathrm{OH}$ pada serat alam dan air. Molekul air pertama kali 
diserap pada gugus hidrofilik dalam serat dan setelah itu molekul air yang lain juga mulai tertarik ke gugus hidrofilik yang lain sehingga nantinya molekul-molekul ini dapat membentuk suatu lapisan di atas molekul air yang telah terserap (Michael et al., 2013).

Adapun menurut Pratiwi (2015) dalam Nurwahida (2019), menyebutkan tingginya kerapatan papan komposit cenderung menurunkan daya serap air papan tersebut. Semakin tinggi kerapatan papan komposit menyebabkan air akan sulit untuk masuk ke dalam rongga-rongga yang ada di dalam papan, karena memiliki pori yang lebih sedikit. Hal ini sesuai dengan hasil uji densitas yang telah dilakukan sebelumnya, yaitu pada komposit dengan densitas yang tinggi cenderung memiliki daya serap air yang rendah. Beberapa faktor yang mempengaruhi penyerapan air pada papan komposit yaitu volume ruang kosong yang dapat menampung air di antara partikel, luas permukaan partikel yang tidak ditutupi matriks dan dalamnya penetrasi matriks terhadap partikel.

Parameter daya serap air tidak ditentukan nilai standarnya baik pada JIS A 5908-2003 maupun SNI 03-2105-2006. Namun demikian papan komposit yang bermutu baik adalah papan yang memiliki daya serap air yang rendah karena besarnya jumlah air yang diserap dapat mengurangi kekuatan papan saat digunakan. Pengujian ini penting dilakukan untuk mengetahui ketahanan papan terhadap air terutama jika penggunaannya untuk keperluan eksterior dimana papan mengalami kontak langsung dengan udara luar (Kartika \& Pratiwi, 2018).

\section{Pengembangan Tebal}

Tabel 4 menunjukkan bahwa setelah perendaman selama 24 jam, pengembangan tebal tertinggi terdapat pada komposit empat lapis dengan arah susunan $0^{\circ}+90^{\circ}+0^{\circ}+90^{\circ}$ yaitu $5,44 \%$. Sedangkan pengembangan tebal terendah terdapat pada komposit tiga lapis dengan arah susunan $0^{\circ}+0^{\circ}+0^{\circ}$ yaitu $0.67 \%$.

Muldatulnia (2016) dalam Nurwahida (2019) menyatakan semakin besar daya serap air maka pengembangan tebal juga bisa semakin besar karena penyerapan air pada bahan dapat merubah ukuran dimensi papan komposit. Namun dalam penelitian ini pengembangan tebal yang tidak sesuai dengan daya penyerapan air. Hal ini disebabkan serat rami tidak merata pada proses pembuatan komposit sehingga berpengaruh juga pada ketersediaan serat tiap potongan spesimen. Selain itu perbedaan tebal tiap spesimen akibat proses penekanan cetakan dengan metode hand layup juga mempengaruhi pengembangan tebal komposit.

Berdasarkan Tabel 4. dapat dilihat bahwa pada pengujian nilai pengembangan tebal diperoleh nilai berkisar antara $0.67 \%$ $5,44 \%$. Seluruh spesimen memenuhi standar nilai pengembangan tebal yang dipersyaratkan JIS A 5908-2003 yaitu maksimal $12 \%$.

\section{PENUTUP}

Penelitian ini berhasil membuat komposit rami epoksi dengan variasi jumlah susunan dan arah sudut multilayer komposit. Variasi jumlah lapisan dan sudut arah serat rami pada komposit mempengaruhi besar densitas komposit. Pada penelitian ini densitas terbesar terdapat pada komposit 4 lapis dengan sudut arah susunan $0^{\circ}$.

Variasi jumlah lapisan dan sudut arah serat rami pada komposit mempengaruhi porositas komposit. Porositas terbesar terdapat pada komposit multilayer dengan arah susunan $0^{\circ}$ karena arah susunan yang seragam menyebabkan lebih banyak gas yang terjebak dalam cetakan pada saat proses pembuatan komposit. 
Variasi sudut arah serat rami pada komposit mempengaruhi daya serap air komposit. Daya serap air terendah terjadi pada komposit dengan arah susunan campuran $0^{\circ}$ dan $90^{\circ}$ karena terdapat sedikit rongga udara yang dapat diisi oleh air. Variasi jumlah lapisan dan sudut arah serat rami pada komposit tidak mempengaruhi pengembangan tebal komposit. Pengembangan tebal komposit dipengaruhi oleh daya serap air, namun dalam penelitian ini daya serap air tidak mempengaruhi pengembangan tebal komposit. Hal ini disebabkan oleh tidak meratanya serat dalam cetakan dan perbedaan tebal tiap spesimen komposit.

Pada penelitian ini terdapat hasil yang tidak sesuai dengan referensi lain. Hal ini disebabkan oleh adanya matriks yang keluar dari cetakan dan pemotongan spesimen yang tidak sama. Oleh sebab itu, peneliti menyarankan pada proses penyiapan spesimen harus diperhatikan dengan seksama agar didapatkan hasil yang optimal.

\section{REFERENSI}

Diharjo, K. (2006). Pengaruh Perlakuan Alkali terhadap Sifat Tarik Bahan Komposit Serat Rami-Polyester. Jurusan Teknik Mesin, 8(1), 8-13.

Faruk, O., Bledzki, A. K., Fink, H. P., \& Sain, M. (2014). Progress Report on Natural Fiber Reinforced Composites. Macromolecular Materials and Engineering, 299(1), 9-26. https://doi.org/10.1002/mame.2013000 08

Firdaus, A. F., Kencanawati, C., \& Priambadi, I. G. N. (2019). Pengaruh Variasi Fraksi Volume Serat Kulit Buah Pinang dengan Getah Pinus sebagai Biocomposite terhadap Kekuatan Tarik dan Porositas. Jurnal Ilmiah Teknik Desain Mekanika, 8(2), 529-532.

Izaak, F. D., Fentje, A. R., \& Romels, L.
(2013). Analisis Sifat Mekanik dan Daya Serap Air Material Komposit Serat Rotan. Jurnal Online Poros Teknik Mesin, 2(2).

Kartika, I. A., \& Pratiwi, D. F. (2018). Karakteristik Papan Partikel dari Bambu dengan Perekat Getah Damar. Jurnal Teknologi Industri Pertanian, 28(2), 127-137. https://doi.org/10.24961/j.tek.ind.pert. 2018.28.2.127

Michael, Surya, E., \& Halimatuddahliana. (2013). Daya Serap Air dan Kandungan Serat (Fiber Content) Komposit Poliester Tidak Jenuh (Unsaturated Polyester) Berpengisi Serat Tandan Kosong Sawit dan Selulosa. Jurnal Teknik Kimia USU, 2(3), 17-21.

Mohammed, L., Ansari, M. N. M., Pua, G., Jawaid, M., \& Islam, M. S. (2015). A Review on Natural Fiber Reinforced Polymer Composite and Its Applications. International Journal of Polymer Science, 1-15. https://doi.org/10.1155/2015/243947

Mujiono, Nurhadiyanto, D., \& Mukhammad, A. F. H. (2017). Ramie Fiber Reinforced Epoxy (RFRE) Composite for Bulletproof Panels. Journal of Fundamental and Applied Sciences, 9(7S), 228-240.

Munasir, M. (2011). Studi Pengaruh Orientasi Serat Fiber Glass Searah dan Dua Arah Single Layer terhadap Kekuatan Tarik Bahan Komposit Polypropylene. Journal of Fundamental and Applied Sciences, 1(1), 33-41. https://doi.org/10.26740/jpfa.v1n1.p33 $-41$

Muslim, J., Sari, N. H., \& Sulistyowati, E. D. (2013). Analisis Sifat Kekuatan Tarik Dan Kekuatan Bending Komposit Hibryd Serat Lidah Mertua Dan Karung Goni Dengan Filler Abu Sekam Padi 5\% Bermatrik Epoxy. Dinamika Teknik Mesin, 3(1), 26-33.

Naidu, A. L., Jagadeesh, V., \& Bahubalendruni, M. V. A. R. (2017). A 
Review on Chemical and Mechanical Properties of Natural Fiber Reinforced Polymer Composites. International Journal of Advanced Research in Engineering and Technology (IJARET), 8(1), 56-68. https://doi.org/10.23940/ijpe.17.02.p8. 189200

Nurwahida. (2019). Uji Sifat Mekanik Papan Komposit dari Campuran Serat Batang Pisang dan Serat Kulit Durian Menggunakan Perekan Polyester. Skripsi Fakultas Sains Dan Teknologi Universitas Islam Negeri Alauddin Makasar.

Nuryati, Amalia, R. R., \& Hairiyah, N. (2020). Pembuatan Komposit dari Limbah Plastik Polyethylene Terephthalate (PET) Berbasis Serat Alam Daun Pandan Laut (Pandanus Tectorius). Jurnal Agroindustri, 10(2), 107-117.

Perdana, D. G. E., Suarsana, K., \& Putri, C. I. (2018). Pengaruh Variasi Komposisi Komposit Matrik Aluminium Berpenguat Sicw / Al2O3 dengan Wetting Agent terhadap Densitas, Porositas dan Kekerasan. Jurnal Ilmiah Teknik Desain Mekanika, 7(1), 7-12.

Purwanto, D. (2016). Sifat Fisis dan Mekanis Papan Partikel dari Limbah Campuran Serutan Rotan dan Sebuk Kayu. Jurnal Riset Industri, 10(3), 125-133.

Reddy, S., \& Mandava, R. (2013). Aero Space Applications of GFRP Composites: Review'. International Journal of Mechanical Engineering Research, 3, 10-14.

Roihan, A., Hartono, R., \& Sucipto, T. (2015). Kualitas Papan Partikel Dari Komposisi Partikel Batang Kelapa Sawit Dan Mahoni Dengan Berbagai Variasi Kadar Perekat Phenol Formaldehida. Peronema Forestry Science Journal, 4(2), 10-18.

Silalahi, R., Sinuhaji, P., \& Simbolon, T. R. (2013). Pembuatan dan Karakterisasi Komposit Serat Kulit Jagung - Poliester dengan Metode Chopped Strand Mat. Saintia Fisika, 4(1), 1-5.

Soemardi, T. P., Kusumaningsih, W., \& Irawan, A. P. (2009). Karakteristik Mekanik Komposit Lamina Serat Rami Epoksi Sebagai Bahan Alternatif Soket Prostesis. MAKARA of Technology Series, 13(2), 96-101. https://doi.org/10.7454/mst.v13i2.487

Wibowo, H., \& Ningsih, T. H. (2018). Pengaruh Variasi Arah Serat pada Susunan Lamina Komposit Serat Glass dengan Matrik Polyester terhadap Sifat Mekanik Hasil Pengujian Bending. Jptm, 7(3), 93-99. 